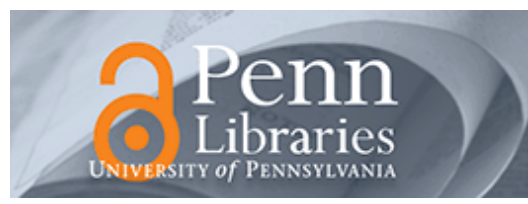

University of Pennsylvania

ScholarlyCommons

8-2016

\title{
The Relative Efficacy of Price Announcements and Express Communication for Collusion: Experimental Findings
}

Joseph E. Harrington Jr

Roberto Hernan Gonzalez

Praveen Kujal

Follow this and additional works at: https://repository.upenn.edu/bepp_papers

Part of the Business Commons, Economics Commons, and the Public Affairs, Public Policy and Public Administration Commons

\section{Recommended Citation}

Harrington, J. E., Gonzalez, R. H., \& Kujal, P. (2016). The Relative Efficacy of Price Announcements and Express Communication for Collusion: Experimental Findings. Journal of Economic Behavior \& Organization, 128 251-264. http://dx.doi.org/10.1016/j.jebo.2016.05.014

This paper is posted at ScholarlyCommons. https://repository.upenn.edu/bepp_papers/44

For more information, please contact repository@pobox.upenn.edu. 


\title{
The Relative Efficacy of Price Announcements and Express Communication for Collusion: Experimental Findings
}

\begin{abstract}
This study conducts experiments to determine the modes of communication that are able to produce and sustain collusion and how the efficacy of communication depends on market structure. Two communication treatments are considered: non-binding price announcements and unrestricted written communication. We find that price announcements are conducive to coordinating on a high price but only under duopoly and when firms are symmetric. The standard experimental finding that collusion without communication is rare when there are more than two firms is shown to be robust to allowing firms to make price announcements. When firms are asymmetric, price announcements do result in higher prices but there is little evidence that firms are coordinating their behavior. When firms are allowed to engage in unrestricted written communication, coordination on high prices occurs for all market structures. We find that the incremental value to express communication (compared to price announcements) is greater when firms are asymmetric and there are more firms.
\end{abstract}

\section{Keywords}

collusion, price announcements, experiments

\section{Disciplines}

Business | Economics | Public Affairs, Public Policy and Public Administration 


\title{
The relative efficacy of price announcements and express communication for collusion: Experimental findings $s^{\text {th }}$
}

\author{
Joseph E. Harrington Jr. ${ }^{\mathrm{a}, *}$, Roberto Hernan Gonzalez ${ }^{\mathrm{b}}$, Praveen Kujal ${ }^{\mathrm{c}}$ \\ a Department of Business Economics E Public Policy, University of Pennsylvania, Philadelphia, PA 19104, USA \\ b Division of Industrial Economics and Finance, University of Nottingham, Nottingham NG8 1BB, UK \\ c Middlesex University, London, UK
}

\section{A R T I C L E I N F O}

\section{Article history:}

Received 14 December 2014

Received in revised form 11 May 2016

Accepted 13 May 2016

Available online 30 May 2016

\section{JEL classification:}

L1

L4

\section{Keywords:}

Collusion

Price announcements

Experiments

\begin{abstract}
A B S T R A C T
This study conducts experiments to determine the modes of communication that are able to produce and sustain collusion and how the efficacy of communication depends on market structure. Two communication treatments are considered: non-binding price announcements and unrestricted written communication. We find that price announcements are conducive to coordinating on a high price but only under duopoly and when firms are symmetric. The standard experimental finding that collusion without communication is rare when there are more than two firms is shown to be robust to allowing firms to make price announcements. When firms are asymmetric, price announcements do result in higher prices but there is little evidence that firms are coordinating their behavior. When firms are allowed to engage in unrestricted written communication, coordination on high prices occurs for all market structures. We find that the incremental value to express communication (compared to price announcements) is greater when firms are asymmetric and there are more firms.
\end{abstract}

(C) 2016 The Author(s). Published by Elsevier B.V. This is an open access article under the CC BY-NC-ND license (http://creativecommons.org/licenses/by-nc-nd/4.0/).

\section{Introduction}

For firms to successfully collude, they must coordinate their behavior, and coordination requires some form of communication. In practice, this communication can involve tacking on a few digits to a multi-million dollar bid as in the FCC spectrum auction (Cramton and Schwartz, 2000) or announcing future intended prices as in the market for air travel (Borenstein, 2004) or unilaterally announcing a pricing strategy as in the truck rental market ${ }^{1}$ or sitting in a hotel room and talking about prices

\footnotetext{
We appreciate the comments of three anonymous referees, an associate editor, the editor, Cedric Argenton, Hans-Theo Normann, Jeroen Hinloopen, Massimo Motta, Matt Weinberg, and attendees of presentations at Drexel University, “Cartels: A Conference in Honor of Robert F. Lanzillotti” (U. of Florida), the 3rd MaCCI Summer Institute in Competition Policy (Edesheim, Germany), and the 11th International Industrial Organization Conference (Northwestern University). This research was partly conducted while the first author was visiting the Universidad Carlos III de Madrid as a Cátedras de Excelencia and the second author was visiting the Economic Science Institute at Chapman University and working at the Universidad de Granada. For financial support, the first author thanks Banco Santander and the National Science Foundation (SES-1148129), and the second and third authors thank the Spanish Government (DGICYT-2012/00103/00) and the International Foundation for Research in Experimental Economics (IFREE). The experiments were run when the second and third authors were visiting the Economic Science Institute at Chapman University.
}

* Corresponding author.

E-mail addresses: harrij@wharton.upenn.edu (J.E. Harrington Jr.), roberto.hernangonzalez@gmail.com (R. Hernan Gonzalez), pkujal@gmail.com (P. Kujal).

${ }^{1}$ Federal Trade Commission, In the Matter of Valassis Communications, Inc., File No. 051 0008, Docket No. C-4160, April 28, 2006. 
and sales quotas as in the lysine market (Eichenwald, 2000). While the last mode of communication is presumably the most effective, it is also the most clearly unlawful. Firms interested in jointly raising prices face a tension in that communication which is more likely to result in coordination may also be more likely to result in prosecution. Hence, they may choose to more indirectly communicate when it is sufficient to produce at least some collusion.

This trade-off raises two questions that we examine here. First, what are the various forms of communication that can produce coordinated collusive outcomes? In particular, how indirect can communication be and still be reasonably effective? This question is central to antitrust and competition law and, in spite of a legion of legal cases that speak to what practices are and are not lawful, there remains a large gray area where legality is unclear. ${ }^{2}$ Second, how does the answer to the first question depend on the structure of the market?

These questions are notoriously difficult to examine theoretically because the equilibrium framework cannot speak to the issue of how firms coordinate in moving from one equilibrium to another which is exactly what is at issue here: What forms of communication will result in firms coordinating a move from a static equilibrium with competitive prices to a dynamic equilibrium with supracompetitive prices? Experimental methods offer a comparative advantage in that subjects engage in exactly the dynamic process of coordination that we are trying to understand. While the subjects are college students and not managers - and thus extrapolating from experiments to market behavior is always a precarious leap - experimental methods have more promise than other methods for shedding light on the effectiveness of various communication practices in producing collusion.

The specific form of those two questions are addressed here as follows. In practice, two commonly observed methods of communication for coordinating firm behavior are advance price announcements (as arose in the ATPCO airlines cases) and unrestricted communication using natural language (as practiced by hard core cartels; for example, lysine, vitamins, and fine arts auction houses). ${ }^{3}$ To assess the relative efficacy of different modes of communication, the research plan is to compare outcomes when sellers can make price announcements with when they cannot, and to compare unrestricted communication (through online chat) with price announcements. When are price announcements effective at producing collusion? When is unrestricted communication particularly effective in producing collusion relative to price announcements? Answers to these questions will shed light on when we can expect firms to engage in the most egregious form of collusion - involving unrestricted communication - and when they will instead choose less express methods. In considering the relative efficacy of these different forms of communication, market structure is varied in terms of the extent of firm heterogeneity and the number of sellers. While unrestricted communication is surely expected to be more effective than price announcements, less clear is how the incremental value of unrestricted communication depends on market structure.

Our main findings are that firms are able to coordinate on a high price with price announcements but only for duopoly and when firms are symmetric. When there are more than two firms, it is a widely-documented experimental finding that collusion is rare without communication and we find that result robust to allowing firms to make price announcements. While price announcements do result in higher prices for an asymmetric duopoly, there is little evidence that they are coordinating their behavior in the sense of acting consistent with a collusive equilibrium. When firms engage in unrestricted communication, coordination on high prices occurs whether firms are symmetric or asymmetric and regardless of the number of firms.

Section 2 provides a brief summary of experimental work pertinent to the current study. Section 3 describes the experimental design as well as the theoretical model underlying the experiment. The results from the experiments are described and discussed in Section 4.

\section{Literature review}

Pertinent to this paper are past studies that experimentally examine how the frequency and extent of supracompetitive outcomes depend on: (1) the method of communication between firms about price or quantity intentions; and (2) firm heterogeneity. There is a voluminous literature addressing the first issue, while the set of experiments addressing the second issue is relatively sparse. There are no experiments that address the interaction of communication and firm heterogeneity, which is the primary focus of the current study. We provide here a brief summary of results from previous experiments, and an extensive review is available in our working paper (Harrington et al., 2013). Previous surveys of the experimental literature on communication of intentions in an oligopoly include Cason (2008), Normann (2008), Haan et al. (2009), and Potters (2009).

The communication protocols used in past oligopoly experiments can be partitioned into four categories. In all of these cases, the announcements made by subjects are non-binding. A Simple Price Announcement protocol involves one or more subjects announcing a price and, in some experiments, subjects responding to an announcement by affirming or rejecting it. An Iterative Price Announcement protocol has multiple stages where price announcements made in an earlier stage restrict the announcements that can be made in the current stage. A Strategy Announcement protocol has subjects announce not a price but a strategy for the game or, more generally, some set of contingency plans. Finally, a Chat protocol allows for either

\footnotetext{
2 Kaplow (2013) delivers an excellent discussion of the boundaries of unlawful collusion.

3 The ATPCO case is covered in Borenstein (2004), while many hard core cartels are discussed in Harrington (2006) and Marshall and Marx (2012).
} 
oral or written communication using natural language with minimal restrictions though typically prohibiting a subject from revealing his or her identity.

The following results are distilled from the experimental literature using those communication protocols (and when no communication is allowed). We have noted papers that tested for the hypothesized behavior though not every paper finds evidence supportive of the noted regularity.

1. Without communication, prices above static Nash equilibrium levels commonly occur when there are two sellers but very rarely occur with more than two sellers (Dufwenberg and Gneezy, 2000; Huck et al., 2004; Engel, 2007; Rojas, 2012; Friedman et al., 2015).

2. Compared to prices when sellers do not communicate, allowing sellers to announce prices results in initially higher prices but then prices decline to levels mildly above or close to levels when communication is prohibited (Holt and Davis, 1990; Cason, 1995; Cason and Davis, 1995; Harstad et al., 1998; Hinloopen and Soetevent, 2008; Bigoni et al., 2012; Cooper and Kühn, 2014).

3. Making communication costly tends to raise price. (Andersson and Wengström (2007) and Andersson and Holm (2013) assume a cost per message, while Hinloopen and Soetevent (2008) and Bigoni et al. (2012) assume probabilistic penalties from all firms agreeing to communicate.)

4. Compared to prices when sellers do not communicate, chat produces significantly higher prices which persist over time (Friedman, 1967; Issac and Plott, 1981; Issac et al., 1984; Davis and Holt, 1998; Dijkstra et al., 2011; Fonseca and Normann, 2012; Cooper and Kühn, 2014).

5. Compared to when firms are symmetric, asymmetric costs result in lower prices (Mason et al., 1992; Mason and Phillips, 1997; Fonseca and Normann, 2008; Dugar and Mitra, 2009; Argenton and Müller, 2012).

Pertinent to the current study, the literature has not addressed the following questions:

- What is the effect of firm heterogeneity on the efficacy of communication?

- What is the effect of firm heterogeneity and the number of firms on the efficacy of unrestricted communication compared to price announcements?

- Do price announcements allow firms (whether symmetric or asymmetric) to effectively collude when there are more than two firms?

\section{Experimental design}

The experimental setting is a variant of the Bertrand price game in which sellers make posted offers, have homogeneous products, and may have different cost functions. In each period, a seller chooses a price and an upper bound on how much it is willing to produce and sell (this choice variable will allow sellers to allocate demand). The horizon is indefinite and the history is common knowledge. Section 3.1 provides a detailed description of the setting. A summary of the equilibrium properties for the game are provided in Section 3.2. The various treatments are described in Section 3.3, and the procedures deployed in conducting the experiments are summarized in Section 3.4.

\subsection{Environment}

Sellers offer identical products and face market demand $D(P)=150-P$ with 150 computerized buyers. ${ }^{4}$ The experiment consists of a multi-period posted-offer market with $n$ participants playing the role of sellers. At the beginning of the experiment, subjects are randomly matched in groups of $n$ people and the match is kept fixed throughout the session. Subjects are told that a session will last for at least 40 periods after which there is an $80 \%$ chance in each period of the session continuing to the subsequent period. ${ }^{5}$

Each seller's cost function is a step-function with the low cost step equaling 10 and the high cost step equaling 54 . Seller $i$ is assigned $k_{i}^{L}$ low cost units and $k_{i}^{H}$ high cost units so the cost function is

$$
C_{i}(q)= \begin{cases}10 q & \text { if } q \in\left\{0,1, \ldots, k_{i}^{L}\right\} \\ 10 k_{i}^{L}+54\left(q-k_{i}^{L}\right) & \text { if } q \in\left\{k_{i}^{L}+1, \ldots, k_{i}^{L}+k_{i}^{H}\right\}\end{cases}
$$

In all treatments, industry capacity is fixed at 24 units of low cost capacity and 180 units of high cost capacity, while the allocation of those units across sellers varies across treatments (and will be described later). Thus, market demand and the industry cost curve are as depicted in Fig. 1.

In each period, subjects simultaneously choose a price and a maximal quantity (to be sold). A subject's total number of units produced and sold equals the minimum of its demand and the maximal quantity it selected. Subjects are told that low

\footnotetext{
${ }^{4}$ There is one buyer with a valuation of 150 , one with a valuation of 149 , and so forth.

${ }^{5}$ The shortest session ran for 40 periods while the longest one lasted for 53 periods.
} 


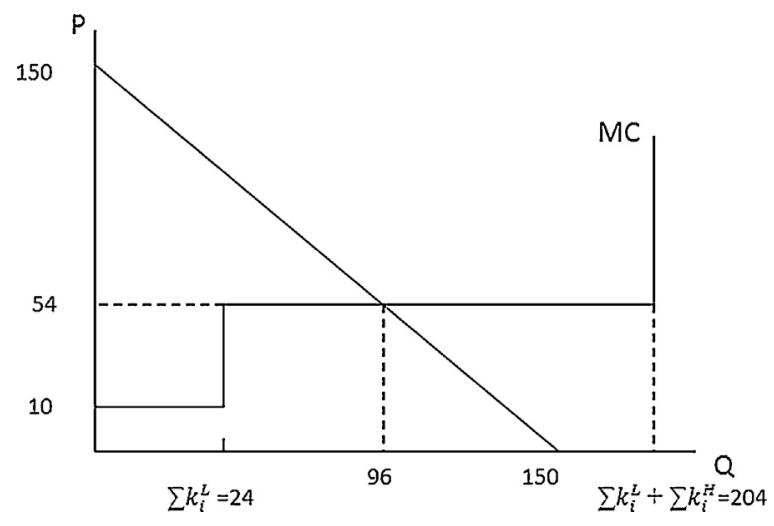

Fig. 1. Industry cost and demand.

cost units will be sold first, and any excess demand will not be carried over to the next period. Sellers only incur costs for the units sold. Subjects have $60 \mathrm{~s}$ to select a price and a maximal quantity, and there is only one price-maximal quantity offer posted by a subject in each period. If a subject chose not to post an offer then he/she earns zero profits for that period. ${ }^{6}$ Once subjects post their price-maximal quantity offers, the market clears. Buyers first purchase from the low price seller until demand or the low price seller's maximal quantity is reached. If there is any residual demand, the process is repeated for the next lowest price seller and this process continues until all demand is met at the prevailing prices or maximal quantities are achieved. Buyers only purchase units if the price is equal to or below their valuation for those units. In case of a tie, the system alternates between sellers - buying a single unit from each seller (with identical prices) - until all available units are exhausted. Subjects are informed about the tie-breaking rule and that the buyers are computerized.

At the end of a period, each subject learns the price-maximal quantity offers of all subjects in their group as well as all subjects' results in terms of units sold and profit earned. They can also review the entire history at any point in time. The environment that subjects face is common knowledge; in particular, they all know market demand, the number of sellers, and each seller's cost function. Subjects are provided with a profit calculator where they can input price-maximal quantity offers for all sellers and learn the resulting profits. They are told: "The profit calculator allows you to estimate your (and others') profits. To do so you can input your price and quantity and make guesses for the other sellers."

The asymmetric treatment involves two firms. One subject is randomly selected to be firm 1 which is given more units of low cost capacity than the other subject playing firm 2, and these roles are kept fixed throughout a session. For all firms, the amount of low cost capacity is set sufficiently low so that each firm's capacity is used up at the static Nash equilibria and at the joint profit maximum. As shown below, this specification has two implications. First, firms have the same ordering over a common price and, in particular, agree that the best common price is 102 . Second, the static Nash equilibria are the same in both the symmetric and asymmetric treatments.

As the two-step marginal cost function departs from the standard specification, let us conclude by highlighting several appealing properties of it. First, under the more common assumption of constant marginal cost, Nash equilibrium involves weakly dominated strategies when firms are symmetric which can cause unstable behavior. With the two-step marginal cost function, Nash equilibrium is not in weakly dominated strategies and firms earn positive profits. Second, under the assumption of constant marginal cost (with a finite price set), there are many Nash equilibria and this indeterminacy could confound the analysis when we compare results for symmetric and asymmetric cost functions. Third, by assuming that the cost asymmetry applies only to a small number of units, the set of static Nash equilibria with the two-step marginal cost function are identical for symmetric and asymmetric treatments, but collusive equilibria can differ (as we show in the next section). Thus, firm asymmetries are relevant only when firms try to collude, which is the focus of this study. ${ }^{7}$

\subsection{Theory}

In the static game, a pure strategy is of the form $(p, r)$ where $p$ is a firm's price and $r$ is a firm's maximal quantity. In characterizing equilibria for the static game, we will allow for mixed strategies. Let $r_{i}(p)$ denote the maximal quantity associated with firm $i$ choosing price $p$ (whether as part of a pure or mixed strategy). Note that when $p>54$ (which, recall, is the cost of high cost capacity units), $r_{i}(p)$ is part of an optimal strategy as long as it is as least as large as residual demand. In

\footnotetext{
${ }^{6}$ A seller posted an offer more than $98 \%$ of the time.

7 Some readers have expressed concern that the experimental setting may be too complex because, in contrast to the usual modeling of Bertrand price competition, marginal cost is a step function and subjects choose a maximal quantity as well as price. In a footnote at the beginning of Section 4.3 , we note that experimental output is consistent with subjects understanding the market setting as reflected in profit-maximizing behavior.
} 
addition, setting the maximal quantity at least as large as market demand $D(p)$ weakly dominates setting it below market demand. We will focus on Nash equilibria in which $r_{i}(p) \geq D(p)$ when $p \geq 54$.

The following proposition holds for the parametric assumptions in the experiment. ${ }^{8}$

Proposition 1. Consider a mixed strategy Nash equilibrium in which $r_{i}(p) \geq D(p) \forall p \geq 54$ in the support of firm i's strategy, $\forall i$. Each firm's strategy assigns probability one to prices in $\{54,55\}$.

The set of Nash equilibria underlying Proposition 1 is composed of all firms pricing at 54 , all firms pricing at 55 , and firms randomizing over 54 and 55 . Thus, the "competitive price" is 54-55.

Turning to the indefinite horizon repeated game, there are obviously many subgame perfect equilibria. To gain some insight, suppose sellers settle on the Nash Bargaining Solution when the choice set is composed of all stationary outcome paths implementable using the grim punishment. ${ }^{9}$ Let us further limit our attention to firms choosing a common price but possibly setting maximal quantities in order to unequally allocate market demand. In this case, it can be shown that firm heterogeneity does not matter in that the resulting outcome is symmetric.

Proposition 2. The Nash Bargaining Solution for the set of outcomes sustainable by grim subgame perfect equilibria is symmetric.

While firms' traits then need not affect collusive behavior, this was shown for just one possible specification of collusion. If an equilibrium has all firms producing at least as much as its low cost capacity (for all histories) then the equilibrium conditions are independent of the amount of low cost capacity. However, consider a strategy profile in which the punishment has the deviator sell zero for some number of periods and, after doing so, there is a return to the collusive outcome. Now equilibrium conditions depend on a firm's low cost capacity because a firm with more low cost capacity foregoes more profit when it produces zero. By affecting the set of equilibrium outcomes from which the cartel selects, firms' traits may then result in an asymmetric outcome.

To pursue this latter point, consider the following strategy profile where the collusive outcome has all firms set a common price and firm $i$ 's share of market demand is $s_{i}$. If a firm deviates from the outcome path, suppose that the punishment has the deviator choose $(p, r)=(55, D(55))$ and the non-deviators choose $(p, r)=(54, D(54))$ for one period - so the deviator sells zero and the non-deviators share market demand at a price of 54 - and then there is a return to the collusive outcome. This punishment applies whether a firm deviates from the original collusive path or the punishment path. Considering this strategy profile at the joint profit maximizing price of 102 and assuming capacities for the asymmetric duopoly treatment $-\left(k_{1}^{L}, k_{2}^{L}\right)=(18,6)$ - it can be shown that all equilibrium conditions are satisfied if and only if $s_{1} \geq .403$ and $s_{2} \geq .504$. Thus, a higher market share for the high cost firm may be required in order to sustain collusion.

Though our analysis of dynamic equilibria is limited, there are two useful takeaways. First, there is a wide class of scenarios whereby the collusive outcome is symmetric even when firms have different cost functions. If firms focus on equilibria in which they always produce at least as much as their low cost capacity (such as with symmetric equilibria constructed on the grim punishment) and the selection of an outcome does not depend on relative profits then the prediction is that the collusive outcome will involve equal market shares. Second, scenarios have been identified whereby the collusive outcome has the firm with fewer units of low cost capacity assigned a higher market share. If the punishment used in equilibrium has the deviator produce zero (for some length of time), it is the higher cost firm's equilibrium condition that is most stringent which means it will need to have more market share.

\subsection{Treatments}

There are three treatment variables: number of firms, seller cost heterogeneity, and communication. The number of firms varied between 2,3 , and 4 . In the symmetric treatment, all sellers have the same number of low cost and high cost units. The asymmetric treatment - which was run only for the case of a duopoly - assumes that both firms have total capacity of 102 units with firm 1 having 18 units of low cost capacity and firm 2 having 6 units of low cost capacity. The various treatments with regards to the number of firms and cost conditions is shown in the bottom row of Table 1 . Finally, there are three communication treatments:

- No Communication: Sellers cannot communicate in any form with their rivals. Sellers simultaneously choose pricemaximal quantity offers and have a maximum of $60 \mathrm{~s}$ to make a decision. If offers are made earlier, the system immediately determines the market outcome and informs sellers of the outcome. Sellers also have the option of not posting an offer by clicking on the "Do not send an offer" button. Sellers have access to the entire history.

- Price Announcement: Sellers are informed that each period of the session consists of two stages. In the first stage (price announcement), sellers simultaneously choose (or not) to make a single non-binding price announcement regarding the price they will select in the market competition stage. Thus, communication between sellers is exclusively numeric and no additional information can be transmitted. Price announcements are simultaneously released to the other sellers. All sellers

\footnotetext{
8 All results in this section are proven and discussed more extensively in Harrington et al. (2013) and are available in the Online Appendix.

9 This specification was used in Harrington (1991) for the duopoly case when $k_{1}^{L}=0$ and $k_{2}^{L}=\infty$ (that is, constant marginal cost that differs between firms). Also see Miklós-Thal (2011) where optimal punishments are considered.
} 
Table 1

Experimental treatments.

\begin{tabular}{|c|c|c|c|c|}
\hline \multirow[t]{2}{*}{ Communication protocol } & \multicolumn{3}{|l|}{ Symmetric } & \multirow{2}{*}{$\begin{array}{l}\text { Asymmetric } \\
n=2\end{array}$} \\
\hline & $n=2$ & $n=3$ & $n=4$ & \\
\hline No communication & SNC2 [12] & SNC3 [8] & & ANC2 [13] \\
\hline Price announcements & SAN2 [12] & SAN3 [8] & SAN4 [6] & AAN2 [12] \\
\hline Chat & $\mathrm{SCH} 2[12]$ & & $\mathrm{SCH} 4[6]$ & $\mathrm{ACH} 2[12]$ \\
\hline Cost treatments $\left(k_{i}^{L}, k_{i}^{H}\right)$ & $(12,90)$ & $(8,60)$ & $(6,45)$ & $(18,84),(6,96)$ \\
\hline
\end{tabular}

know that all price announcements are non-binding, and that they can choose not to make an announcement. ${ }^{10}$ While the first stage can last for up to $60 \mathrm{~s}$, it immediately goes to the second stage if all announcements are made before the time limit. As in the No Communication treatment, the second stage has them simultaneously make price-maximal quantity offers. All information is common and sellers have access to the entire history, including all sellers' announcements.

- Chat: Sellers are informed that each period of the session consists of two stages. In the first stage, they can participate in an online chat room where they communicate with the other seller(s) for $60 \mathrm{~s}$. The communication protocol is explicitly explained to the participants: "You are free to discuss any aspects of the experiment, with the following exceptions: you may not reveal your name, discuss side payments outside the laboratory, or engage in inappropriate language (including such shorthand as 'WTF'). If you do, you will be excused and you will not be paid." As in the No Communication treatment, the second stage has them simultaneously make price-maximal quantity offers. Sellers have access to the entire history, including all sellers' messages.

The No Communication treatment describes the usual environment in which firms can only coordinate by signaling through their actual transaction prices. The Price Announcement treatment captures a feature of some markets in which firms can make non-binding announcements about future prices. For example, advance price announcements have been deployed and argued to have produced supracompetitive prices in steel (Scherer, 1980), airlines (Borenstein, 2004), and diesel and petrol fuel in Taiwan (Fair Trade Commission Decision, 2004). ${ }^{11}$ The Price Announcement treatment is designed to give firms an instrument by which to coordinate that is short of express communication. The issue is whether price announcements are sufficiently informative to induce coordinated behavior. ${ }^{12}$ Finally, the Chat treatment models explicit collusion in that firms can engage in unrestricted communication in order to coordinate on a collusive outcome and engage in an exchange of assurances.

Table 1 summarizes the different combination of treatments used in the experiment along with the notation we will use when referring to the treatment. In brackets [ ] is the number of sessions run with that treatment. Given the large number of possible combinations, the number of sellers-firm heterogeneity treatments were chosen to make the best use of our budget by avoiding treatments that were unlikely to provide new information. For example, if $n$ firms for a treatment yielded competitive results then we did not run the treatment with more than $n$ firms as it is likely to produce competitive results.

\subsection{Procedures}

Our subject pool consisted of students from Chapman University which is a major American university with a diverse population. Participants were recruited by email from a pool of more than 2000 students who had signed up to participate in experiments. Emails were sent to a randomly selected subset of the pool of students. Subjects were recruited for a total of two hours. The experiments took place in May 2011. In total, 242 students participated in 73 duopoly, 16 triopoly and 12 quadropoly experiments.

The instructions were displayed on subjects' computer screens and they were told that all screens displayed the same set of instructions. They had exactly $20 \mathrm{~min}$ to read the instructions (which are provided in theOnline Appendix). A 20-min timer was shown on the laboratory screen. Three minutes before the end of the instructions period, a monitor entered the room announcing the time remaining and handing out a printed copy of the summary of the instructions. None of the participants asked for extra time to read the instructions. At the end of the 20-min instruction round, the experimenter closed the instructions file from the server, and subjects typed their names to start the session. The interaction between the experimenter and the participants was negligible.

\footnotetext{
10 A seller can either click the button "Do not send an announcement" or not submit an announcement and wait until the end of the announcement period.

11 In our experiment, price announcements can only affect seller behavior because buyers are simulated and, even if buyers were live, they would be irrelevant to buyer behavior. It is then best to think of the Price Announcement treatment as relevant to markets in which these announcements are not received by buyers (for example, they occur through a trade association) or where such information is of little value to buyers.

12 We intentionally did not allow firms to also announce maximal quantities because such quantity announcements are very uncommon though have occurred in the automobile industry (Doyle and Snyder, 1999).
} 
Table 2

Average market price. Average (median) [Std. Dev] market price.

\begin{tabular}{|c|c|c|c|c|c|c|c|c|c|c|}
\hline \multirow[b]{2}{*}{ Periods } & \multicolumn{3}{|c|}{ No communication } & \multicolumn{4}{|c|}{ Price Announcements } & \multicolumn{3}{|l|}{ Chat } \\
\hline & $\mathrm{SNC2}$ & ANC2 & $\overline{\mathrm{SNC3}}$ & SAN2 & AAN2 & SAN3 & SAN4 & $\mathrm{SCH} 2$ & $\mathrm{ACH} 2$ & $\mathrm{SCH} 4$ \\
\hline $1-40$ & $\begin{array}{l}66.7 \\
(63.4) \\
{[11.8]}\end{array}$ & $\begin{array}{l}61.5 \\
(57.8) \\
{[10.9]}\end{array}$ & $\begin{array}{l}58.5 \\
(56.8) \\
{[8.1]}\end{array}$ & $\begin{array}{l}76.2 \\
(72.6) \\
{[17.6]}\end{array}$ & $\begin{array}{l}67.5 \\
(65.7) \\
{[5.9]}\end{array}$ & $\begin{array}{l}58.0 \\
(55.7) \\
{[4.6]}\end{array}$ & $\begin{array}{l}61.2 \\
(61.0) \\
{[7.4]}\end{array}$ & $\begin{array}{l}91.2 \\
(92.7) \\
{[12.5]}\end{array}$ & $\begin{array}{l}91.2 \\
(90.4) \\
{[17.6]}\end{array}$ & $\begin{array}{l}89.6 \\
(94.7) \\
{[17.1]}\end{array}$ \\
\hline $1-20$ & $\begin{array}{l}64.0 \\
(61.3) \\
{[11.7]}\end{array}$ & $\begin{array}{l}60.0 \\
(56.6) \\
{[12.4]}\end{array}$ & $\begin{array}{l}60.7 \\
(56.0) \\
{[15.9]}\end{array}$ & $\begin{array}{l}72.9 \\
(64.5) \\
{[18.1]}\end{array}$ & $\begin{array}{l}64.4 \\
(64.3) \\
{[7.3]}\end{array}$ & $\begin{array}{l}58.3 \\
(56.1) \\
{[5.3]}\end{array}$ & $\begin{array}{l}63.2 \\
(63.9) \\
{[8.8]}\end{array}$ & $\begin{array}{l}83.5 \\
(83.8) \\
{[18.4]}\end{array}$ & $\begin{array}{l}82.7 \\
(83.5) \\
{[20.2]}\end{array}$ & $\begin{array}{l}85.7 \\
(87.2) \\
{[16.8]}\end{array}$ \\
\hline $21-40$ & $\begin{array}{l}69.5 \\
(64.1) \\
{[17.1]}\end{array}$ & $\begin{array}{l}63.0 \\
(56.9) \\
{[14.3]}\end{array}$ & $\begin{array}{l}56.3 \\
(55.6) \\
{[2.2]}\end{array}$ & $\begin{array}{l}79.5 \\
(76.5) \\
{[20.2]}\end{array}$ & $\begin{array}{l}70.6 \\
(72.8) \\
{[9.4]}\end{array}$ & $\begin{array}{l}57.7 \\
(55.8) \\
{[4.3]}\end{array}$ & $\begin{array}{l}59.2 \\
(55.5) \\
{[7.9]}\end{array}$ & $\begin{array}{l}98.9 \\
(102.0) \\
{[8.6]}\end{array}$ & $\begin{array}{l}99.5 \\
(99.8) \\
{[17.2]}\end{array}$ & $\begin{array}{l}93.4 \\
(102.0) \\
{[18.5]}\end{array}$ \\
\hline
\end{tabular}

The show-up fee was $\$ 7.00$ and average payoffs (including the show-up fee) varied from a low of $\$ 18.85$ (which was for triopoly with the No Communication treatment) to a high of $\$ 34.35$ (which was for duopoly with the Chat treatment).

\section{Results}

Our interest is understanding the conditions under which subjects settle down on a collusive equilibrium. When collusion does emerge, we do not generally expect it to occur immediately for a subject may go through a learning phase as she seeks to become better informed about the market environment and other subjects' strategies. For this reason, results are reported for periods $1-20,21-40$, and $1-40 .{ }^{13}$ We expect results for periods 21-40 to be most informative and, in fact, there is evidence of learning in the early periods as revealed both through choices and in the messages from the Chat treatment.

\subsection{Baseline: no communication}

Let us begin by considering the benchmark protocol of No Communication (NC). Table 2 reports the mean, median, and standard deviation of average market price. ${ }^{14}$ We test whether market prices are equal to (or exceed) the competitive price using a non-parametric test in light of the small number of observations and that market price is not normally distributed. ${ }^{15}$ Mean and median market price exceed 55 in all treatments so it is at least as high as the static Nash equilibrium price of 54-55. Average market price is significantly higher for symmetric duopoly with a price of 69.5 ( $p$-value $=.003$ ) and for asymmetry duopoly with a price of 63.0 ( $p$-value $=.011$ ). In contrast, the average market price for symmetric triopoly is 56.3 which is very close to the competitive price $(p$-value $=.363)$.

Consistent with previous findings in the experimental literature, supracompetitive prices occur with two sellers but not with three sellers. We also find for the case of a duopoly that prices are higher when firms' cost functions are identical though it is only barely statistically significant. For periods $1-40$, prices are higher under symmetry by $8.5 \%(p$-value $=.103$; see Table 4$)$, and are higher for periods $21-40$ by $10.3 \%(p$-value $=.128)$.

Result 1. For the case of no communication, average market price exceeds the competitive level in duopoly (symmetric and asymmetric) but not in triopoly (symmetric). For the case of duopoly and no communication, average market price is higher when firms have identical cost functions than when they have different cost functions (though the difference is not statistically significant at conventional levels).

\subsection{Signaling: price announcements}

In assessing the effect of the communication protocol on behavior and how its effect depends on market structure, it is important to note that collusion is more than high prices; it is a mutual understanding among firms to coordinate their behavior which is formally expressed as a collusive equilibrium for an indefinite horizon game. Prices could be high and yet firms may not be colluding. For example, firms may periodically raise price in order to attempt to coordinate a move to a collusive equilibrium but never succeed in doing so; high average prices are then the product of failed attempts to collude. Or sellers may engage in randomized pricing that periodically results in high prices - thus producing high average prices - but again there is not the regularity in prices one would typically associate with a collusive equilibrium. In the

\footnotetext{
${ }^{13}$ Recall that the length of the horizon is 40 periods for sure and is then stochastically terminated. There was no evidence of end-game effects before or after period 40.

${ }^{14}$ The market price is the sum of firms' prices weighted by the firm's market shares, and the average market price for a group is the market price averaged across all periods (and is the unit of observation for calculating the statistics in Table 2).

${ }^{15}$ The histograms on market price are available in the Online Appendix. A one-sided sign test is used for which the null hypothesis is median market price $=55$ and the alternative hypothesis is median market price $>55$. Given that theory predicts that price will not be less than the static Nash equilibrium price but could exceed it, a one-sided test seems appropriate.
} 
Table 3

Coordination measures (duopoly).

\begin{tabular}{|c|c|c|c|c|c|c|c|}
\hline & \multirow[b]{2}{*}{ Periods } & \multicolumn{2}{|c|}{ No communication } & \multicolumn{2}{|c|}{ Price announcements } & \multicolumn{2}{|l|}{ Chat } \\
\hline & & SNC2 & ANC2 & SAN2 & AAN2 & $\mathrm{SCH} 2$ & $\mathrm{ACH} 2$ \\
\hline \multirow{3}{*}{$\begin{array}{l}\text { Number of periods } \\
\text { with equal price } \\
(p>55)\end{array}$} & $1-40$ & 5.3 & 4.0 & 13.0 & 4.3 & 29.5 & 17.7 \\
\hline & $1-20$ & 1.8 & 2.2 & 4.0 & 1.4 & 11.2 & 6.7 \\
\hline & $21-40$ & 3.5 & 1.8 & 9.0 & 2.9 & 18.3 & 11.0 \\
\hline \multirow{3}{*}{$\begin{array}{l}\text { Duration of price } \\
\text { coordination }(p>55)\end{array}$} & $1-40$ & 2.5 & 1.7 & 9.8 & 1.8 & 23.0 & 11.8 \\
\hline & $1-20$ & 1.0 & 1.3 & 2.7 & 0.8 & 8.5 & 5.2 \\
\hline & $21-40$ & 2.3 & 1.2 & 7.8 & 1.5 & 17.3 & 8.7 \\
\hline
\end{tabular}

ensuing analysis, sellers will be said to be colluding when prices are high and follow some stable pattern. This could mean consistently setting identical prices and equally sharing demand. Or firms could consistently set different prices with the firm with the lower (but still high) price restricting its supply so that the firm with the higher price has residual demand. Or firms could alternate over time with one firm selling to the market and the other firm pricing itself out of the market or not participating. Recognizing the different forms that supracompetitive outcomes can take, various measures will be used in our analysis.

As an initial step, let us focus on collusion that takes the form of firms setting identical supracompetitive prices. To identify the extent to which price announcements results in such an outcome, we will report average market price and two measures of coordination: the number of periods for which sellers set the same price exceeding the competitive price (Same) and the longest number of consecutive periods for which sellers set identical prices (Duration). Sellers achieving a high average price and high measures of Same and Duration is compelling evidence that they are colluding. If sellers achieve a high average price and low measures of coordination then it could either be that firms are not colluding or are colluding in a different manner.

In going from the No Communication to the Price Announcement treatment, Table 2 reports that the average market price under duopoly substantially increases, whether firms are symmetric or asymmetric. Using a Mann-Whitney-Wilcoxon test (see Table 4), this difference is statistically significant for asymmetric duopolies (e.g., $p$-value $=.004$ for periods 1 -40) but only marginally so for symmetric duopolies (e.g., $p$-value $=.133$ for periods $1-40$ ). Though the increase in average price is actually larger in absolute and percentage terms when firms are symmetric, the standard deviation is much larger. We will return to this point later.

Having the ability to make price announcements proves insufficient to produce collusion when there are more than two firms. For symmetric triopolies, average price is 57.7 (periods 21-40) which is close to average price without announcements (56.3) and to the competitive price (54-55). Similar results were found in six sessions conducted with four symmetric firms. In sum, price announcements matter when there are two sellers - whether symmetric or asymmetric - but not when there are more than two sellers.

One of the most robust findings in the experimental literature on collusion is that, in the absence of communication, three or more firms very rarely collude. Our results show this result to be robust to allowing communication to occur through price announcements. There is a fundamental difference in the strategic uncertainty faced by two firms and by more than two firms. With a duopoly, a firm that announces a high price need only convince the other firm that it intends to set a high price in order to induce that rival firm to also set a high price. But that is insufficient when there are three firms. The announcement of a high price by firm 1 may convince firms 2 and 3 that firm 1 intends to raise price but firm 2 may be uncertain as to whether firm 3 drew the same inference and thus uncertain as to whether firm 3 will raise price. Our results suggest that price announcements are inadequate for surmounting the challenge of higher order beliefs necessary to achieve collusion when there are more than two firms.

While price announcements are producing higher average prices for duopolies, have firms coordinated on a stable pattern of prices? Examining the coordination measures in Table 3, there is more than a doubling in the number of periods in which firms in a symmetric duopoly set identical prices, as it increases from 5.3 to 13.0. It is even more impressive if we focus on periods 21-40 where the frequency of identical prices rises from $18 \%$ of the time to almost $45 \%$. Furthermore, this higher frequency of equal prices is time-dependent: Probit regressions show that the probability that firms' prices are identical in the current period is higher when they were identical in the previous period. ${ }^{16}$ The Duration measure tells the same story, as the average maximal number of consecutive periods for which firms set the same price goes from 2-3 to 7-8 periods. In contrast, price announcements do not produce any increase in the coordination measures when firms are asymmetric. Though the differences for symmetric firms are not statistically significant by the usual standards (see Table 4), the evidence is suggestive that price announcements are producing more coordination for symmetric duopolies.

\footnotetext{
${ }^{16}$ A series of probit regressions were run where the dependent variable was a dummy for whether both firms in the market set the same price (above 55) or not, and have the one-period lag of the dependent variable as the regressor. The estimated coefficient on the regressor is always positive and significant in all of the duopoly treatments (all $p$-values $<.05$ ), for periods 1 -40. Similar results occur for periods $21-40$ (all $p$-values $<.029$ ), except for treatments SNC2 and AAN2. These results are available in the Online Appendix.
} 
Table 4

Mann-Whitney-Wilcoxon tests. $p$-Values for the test that the average Market Price, Same or Duration is the same across two treatments, for periods $1-40$ $(1-20)[21-40]$.

\begin{tabular}{|c|c|c|c|c|}
\hline Treatment 1 & Treatment 2 & Average market price & Same & Duration \\
\hline \multirow[t]{4}{*}{ SNC2 } & SAN2 & $.133(.184)[.273]$ & $.368(.549)[.170]$ & $.211(.583)[.084]$ \\
\hline & $\mathrm{SCH} 2$ & $<.001(.008)[<.001]$ & $<.001(<.001)[<.001]$ & $<.001(.002)[<.001]$ \\
\hline & SNC3 & .045 (.487) [.009] & $.015(.213)[.014]$ & $.014(.246)[.003]$ \\
\hline & ANC2 & $.103(.828)[.128]$ & $.225(.955)[.095]$ & $.264(.929)[.068]$ \\
\hline \multirow[t]{4}{*}{ SAN2 } & $\mathrm{SCH} 2$ & $.057(.184)[.022]$ & $.008(.015)[.002]$ & $.009(.010)[.002]$ \\
\hline & SAN3 & $.009(.031)[.005]$ & $.002(.373)[<.001]$ & $.004(.368)[<.001]$ \\
\hline & SAN4 & $.039(.454)[.011]$ & $.002(.135)[.001]$ & $.003(.148)[.001]$ \\
\hline & AAN2 & $.525(.453)[.419]$ & $.092(.717)[.048]$ & $.114(.925)[.047]$ \\
\hline \multirow[t]{2}{*}{$\mathrm{SCH} 2$} & $\mathrm{SCH} 4$ & .925 (>.999) [.758] & $.963(.706)[.210]$ & $.510(.851)[.071]$ \\
\hline & $\mathrm{ACH} 2$ & $.564(.817)[.231]$ & $.046(.111)[.011]$ & $.022(.147)[.005]$ \\
\hline SNC3 & SAN3 & $.916(.674)[.529]$ & $.337(.386)[.487]$ & $.143(.333)[.535]$ \\
\hline SAN3 & SAN4 & $.699(.366)[>.999]$ & $.330(.370)[.386]$ & $.411(.411)[.386]$ \\
\hline SAN4 & $\mathrm{SCH} 4$ & $.016(.025)[.006]$ & $.013(.013)[.007]$ & $.013(.013)[.007]$ \\
\hline \multirow[t]{2}{*}{ ANC2 } & AAN2 & $.004(.211)[.017]$ & $.825(.737)[.519]$ & $.657(.346)[.414]$ \\
\hline & $\mathrm{ACH} 2$ & $<.001(.002)[<.001]$ & $.009(.123)[.009]$ & $.008(.093)[.005]$ \\
\hline AAN2 & $\mathrm{ACH} 2$ & $<.001(.008)[<.001]$ & $.015(.056)[.026]$ & $.015(.032)[.025]$ \\
\hline
\end{tabular}

SNC2 - symmetric, no communication, duopoly; SNC3 - symmetric, no communication, triopoly; SAN2 - symmetric, price announcement, duopoly; SAN3 symmetric, price announcement, triopoly; SCH2 - symmetric, chat, duopoly; SCH4 - symmetric, chat, quadropoly; ANC2 - asymmetric, no communication, duopoly; AAN2 - asymmetric, price announcement, duopoly; ACH2 - asymmetric, chat, duopoly.

Bold values refer to $p$-values lower than 0.1 .

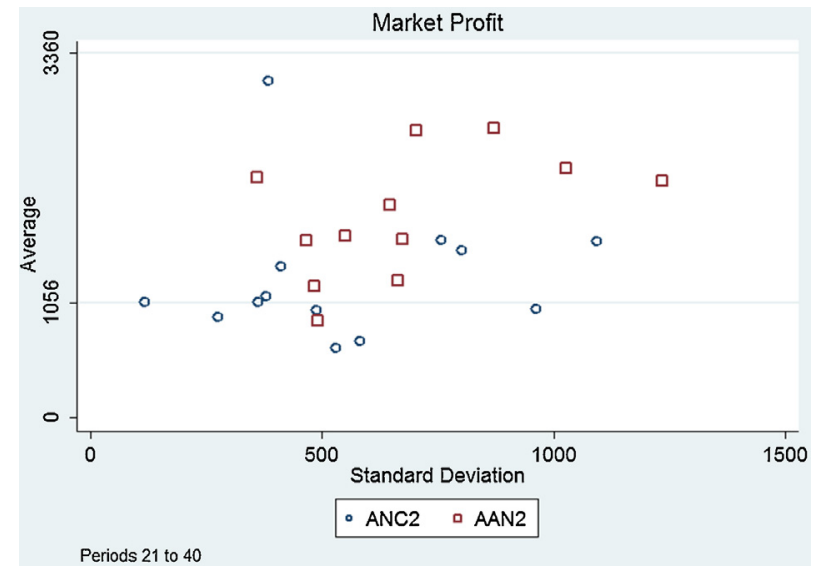

Fig. 2. Mean and standard deviation of profit - asymmetric duopoly (No Communication and Price Announcement treatments).

Of course, the lack of evidence for increased coordination in asymmetric duopolies may just reflect the inadequacy of our measures. Same and Duration are designed to detect coordination on identical prices. Perhaps, due to cost differences, asymmetric duopolies collude with different prices and choose maximal quantities so as to allocate market demand, or instead alternate in supplying the entire market. If firms have settled down to such supracompetitive outcomes then this will be reflected in high and stable industry profit.

Figs. 2 and 3 report the mean and standard deviation of industry profit over periods $21-40$ for asymmetric and symmetric duopolies, respectively, and for both the No Communication and Price Announcement treatments. ${ }^{17}$ Collusion is associated with the northwest quadrant where industry profit is high with low volatility. Examining Fig. 2, price announcements raise average industry profit for asymmetric duopolies but there are no observations of high and stable profit (relative to when firms are not permitted to make price announcements). In contrast, price announcements result in noticeably higher and less variable profit for one-third of the symmetric duopolies. For those four duopolies, industry profit is higher and the standard deviation is lower than in any of the 12 symmetric duopolies in the No Communication treatment. This evidence is consistent with price announcements increasing the extent of collusion for symmetric duopolies but not for asymmetric duopolies. $^{18}$

\footnotetext{
17 The joint profit maximum yields profit of 3360, while industry profit is 1056 when all firms set a price of 54 .

18 These measures look at the mean and standard deviation for periods 21-40. A duopoly could succeed in colluding late in the horizon and thereby fail to have a high stable profit in this 20 period window. Inspection of the time series for all of the groups reveals only two such cases.
} 


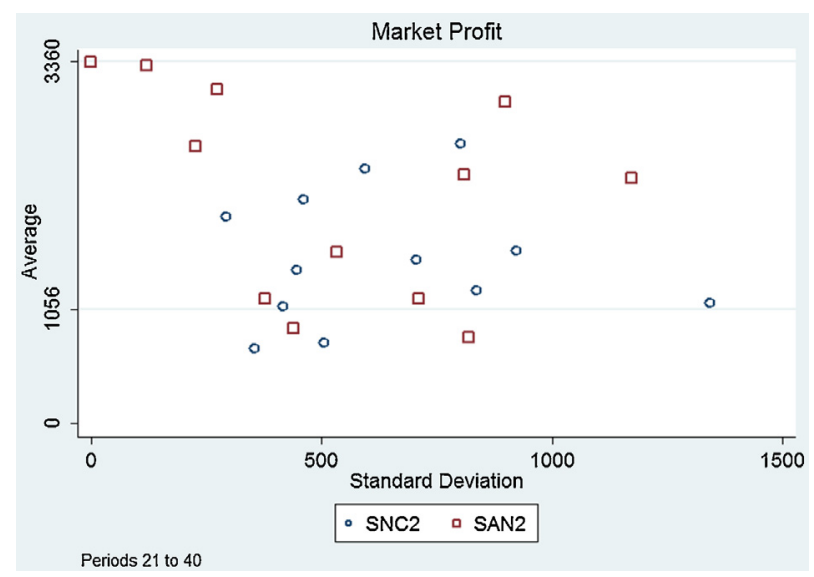

Fig. 3. Mean and standard deviation of profit - symmetric duopoly (No Communication and Price Announcement treatments).

Result 2. When firms can make price announcements then - compared to no communication - firms in a duopoly set higher prices whether they are symmetric or asymmetric, but firms coordinate more only when they are symmetric. When there are more than two firms, price announcements do not result in supracompetitive prices.

There is a rather natural explanation for why price announcements are more effective in producing collusion when firms are symmetric. When sellers have identical cost functions, a symmetric supracompetitive outcome is focal, and can be implemented by coordinating on identical prices. However, when sellers have different cost functions, a symmetric outcome is no longer focal. An asymmetric outcome could be produced in a variety of ways but arguably the most straightforward is for sellers to set identical prices and unequally allocate market demand, which is what has been done with many cartels (Harrington, 2006). For example, if sellers wanted to support the joint profit maximum and have the high cost seller receive $60 \%$ of market demand, both sellers could charge the monopoly price of 102 , which yields market demand of 48 , and have the low cost seller set its maximal quantity equal to 19, which will result in the high cost seller supplying the residual demand of 29. However, this collusive outcome requires coordination of prices and quantities. The difficulty in coordinating on equal prices and unequal quantities in the Price Announcement treatment is that sellers are only allowed to announce prices. Of course, just because an asymmetric outcome may be the most desirable collusive outcome for an asymmetric duopoly, it does not imply that firms would try to coordinate on it. If it is perceived to be too difficult then they could decide to coordinate on identical prices and equally share market demand; some collusion is better than competition. However, that is not what we are finding. Under asymmetric duopoly, sellers are not coordinating on a common price.

To complement the preceding nonparametric analysis, panel data regressions were conducted to measure the effect on market price of the communication protocols and cost structures. The empirical model is: $p_{i, t}=\mu_{o}+\beta X_{i, t}^{\prime}+e_{i, t}$, where $p_{i, t}$ is the market price in group $i$ in period $t$ and $X_{i, t}^{\prime}$ are dummy variables for each treatment. Similar to previous studies, we allow for serial autocorrelation of the disturbance. ${ }^{19}$ The model was estimated for duopolies and for periods 1-20, 21-40, and 1-40. In Table 5, DAnn is a dummy variable that takes the value 1 for the Price Announcement treatment (and value 0 for the No Communication treatment), DAsym is a dummy variable that takes the value 1 for the asymmetric cost treatment, and we also have an interaction term for the communication and cost treatments.

Confirming Result 2, the coefficient on DAsym is negative (and significant except for periods 1-20) indicating that, when communication is prohibited, prices are lower when firms are asymmetric. Permitting firms to make price announcements raises price by 10 for symmetric duopolies and 7.64 for asymmetric duopolies (using the estimated coefficients for periods 21-40). While the negative coefficient on the interaction term DAnn $\times$ DAsym is consistent with the claim that indirect communication through price announcements is a more effective collusive device when firms are symmetric, it is not significant.

Let us now return to the issue of the high standard deviation for average market price for a symmetric duopoly under the Price Announcement treatment (see Table 2). An inspection of the price paths for individual groups reveal that, under symmetric duopoly, sellers either set high identical prices ( 5 out of 12 groups) or prices near competitive levels with some unsuccessful forays into supracompetitive territory (5 out of 12 groups). ${ }^{20}$ It is this dichotomy in outcomes which we believe is responsible for the high standard deviation: Either firms have great success in colluding or very little success. Such a property is not found for the case of asymmetric duopoly. These claims are supported by Fig. 4 where an observation is a

\footnotetext{
19 See Mason et al. (1992), Mason and Phillips (1997), and Argenton and Müller (2012).

${ }^{20}$ Price paths for all 12 groups are available in the Online Appendix.
} 
Table 5

Duopoly market price - no communication vs. price announcements.

\begin{tabular}{|c|c|c|c|}
\hline Periods & $\begin{array}{l}\text { Regression } 1 \\
1-20\end{array}$ & $\begin{array}{l}\text { Regression } 2 \\
21-40\end{array}$ & $\begin{array}{l}\text { Regression } 3 \\
1-40\end{array}$ \\
\hline Constant & $\begin{array}{l}64.00^{* * * *} \\
(2.52)\end{array}$ & $\begin{array}{l}69.47^{* * *} \\
(2.07)\end{array}$ & $\begin{array}{l}66.74^{* * *} \\
(1.66)\end{array}$ \\
\hline DAnn & $\begin{array}{l}8.93^{* * * *} \\
(3.46)\end{array}$ & $\begin{array}{l}10.00^{* * *} \\
(3.20)\end{array}$ & $\begin{array}{l}9.46^{* * * *} \\
(2.40)\end{array}$ \\
\hline DAsym & $\begin{array}{l}-4.04 \\
(3.26)\end{array}$ & $\begin{array}{l}-6.46^{* *} \\
(2.67)\end{array}$ & $\begin{array}{l}-5.25^{* *} \\
(2.15)\end{array}$ \\
\hline DAnn $\times$ DAsym & $\begin{array}{l}-4.48 \\
(4.27)\end{array}$ & $\begin{array}{l}-2.36 \\
(3.94)\end{array}$ & $\begin{array}{l}-3.42 \\
(2.97)\end{array}$ \\
\hline$F(3,976)$ & $5.80^{* * *}$ & $10.59^{* * *}$ & \\
\hline$F(3,1956)$ & & & $14.89^{* * *}$ \\
\hline$N$ & 980 & 980 & 1960 \\
\hline
\end{tabular}

DAnn is a dummy variable which takes value 1 if firms can make price announcements and value 0 otherwise. DAsym is a dummy variable which takes value 1 if firms cost functions are asymmetric and value 0 otherwise. Newey-West standard errors in parentheses. ${ }^{*} p$-Value $<.10$.

*** $p$-Value $<.05$.

*** $p$-Value $<.01$.

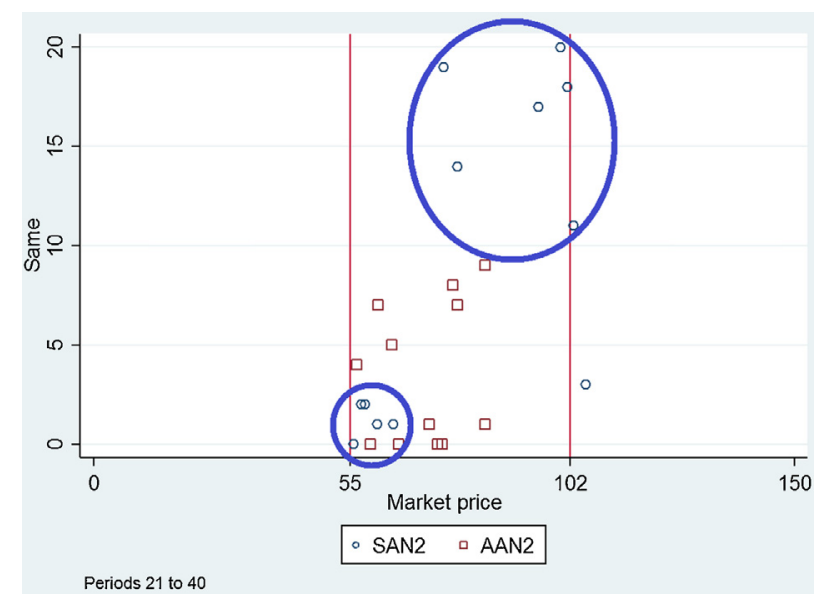

Fig. 4. Average market price and coordination (same), price announcement: symmetric and asymmetric duopolies.

group's average market price and the number of periods for which firms set the same price. When firms are symmetric, the observations form two (circled) clumps; one with low price and low coordination, and the other with high price and high coordination (with the exception of one group with high price and low coordination). Note that the lowest average price for the groups in the "high Same" clump exceeds the highest average price for the groups in the "low Same" clump. Also, 5 out of the 12 symmetric duopoly groups have average price close to the monopoly price of 102 . When firms are asymmetric, there is no apparent relationship between average price and the frequency with which firms set the same price.

Summarizing this section, the ability to make non-binding price announcements produces more collusion - as reflected in stable supracompetitive outcomes - only for symmetric duopolies. For symmetric duopolies, if price announcements are able to produce collusion then the collusion is often near-maximal in that sellers consistently set prices near the monopoly level. While price announcements do raise average prices for asymmetric duopolies, there is little evidence that sellers are coordinating; they do not set common prices, and an examination of profit does not support coordination on an asymmetric outcome.

\subsection{Express communication: Chat}

Turning to the Chat treatment, collusion is rampant; sellers set high and identical prices most of the time and in almost all groups. From Table 2 for the symmetric case, average price is 91.2 over periods $1-40$ (which is $77 \%$ of the gap between the competitive and monopoly prices) and is 98.9 over periods $21-40$ (93\% of the gap). Even more impressive, the median price is the monopoly price of 102 (periods 21-40). Prices are just as high when the duopoly has asymmetric firms with an average price of 91.2 for periods $1-40$ and an average price of 99.5 for periods $21-40$. Finally, when there are more than two 
Table 6

Asymmetric duopoly with chat (periods 21-40).

\begin{tabular}{|c|c|c|c|c|c|c|}
\hline Group & $\begin{array}{l}\text { Average } \\
\text { market price }\end{array}$ & $\begin{array}{l}\text { Median market } \\
\text { price }\end{array}$ & $\begin{array}{l}\text { Number of } \\
\text { periods with } \\
\text { equal price }\end{array}$ & $\begin{array}{l}\text { Firm } 1 \text { (low cost) } \\
\text { Average profit }\end{array}$ & $\begin{array}{l}\text { Firm } 2 \text { (high cost) } \\
\text { Average profit }\end{array}$ & $\begin{array}{l}\text { Firm } 1 \text { (low cost) } \\
\text { Average market } \\
\text { share }\end{array}$ \\
\hline 1 & 102.0 & 102.0 & 20 & 1944 & 1416 & $50 \%$ \\
\hline 2 & 144.5 & 145.0 & 1 & 335 & 304 & $53 \%$ \\
\hline 3 & 100.9 & 102.0 & 16 & 1629 & 1601 & $41 \%$ \\
\hline 4 & 95.6 & 95.0 & 4 & 1148 & 1654 & $35 \%$ \\
\hline 5 & 102.7 & 103.0 & 18 & 1753 & 1523 & $45 \%$ \\
\hline 6 & 84.4 & 84.4 & 0 & 1440 & 1440 & $30 \%$ \\
\hline 7 & 98.0 & 101.0 & 17 & 1603 & 1640 & $38 \%$ \\
\hline 8 & 99.0 & 102.0 & 18 & 1904 & 1287 & $50 \%$ \\
\hline 9 & 102.0 & 102.0 & 20 & 1944 & 1416 & $50 \%$ \\
\hline 10 & 96.4 & 102.0 & 1 & 1428 & 1186 & $54 \%$ \\
\hline 11 & 68.6 & 64.5 & 1 & 1057 & 555 & $56 \%$ \\
\hline 12 & 100.6 & 99.0 & 16 & 1795 & 1451 & $47 \%$ \\
\hline
\end{tabular}

Table 7

Duopoly market price - price announcements vs. chat.

\begin{tabular}{|c|c|c|c|}
\hline Periods & $\begin{array}{l}\text { Regression } 1 \\
1-20\end{array}$ & $\begin{array}{l}\text { Regression } 2 \\
21-40\end{array}$ & $\begin{array}{l}\text { Regression } 3 \\
1-40\end{array}$ \\
\hline Constant & $\begin{array}{l}72.93^{* * *} \\
(2.37)\end{array}$ & $\begin{array}{l}79.47^{* * *} \\
(2.45)\end{array}$ & $\begin{array}{l}76.20^{* * *} \\
(1.74)\end{array}$ \\
\hline DChat & $\begin{array}{l}10.38^{* * * *} \\
(3.83)\end{array}$ & $\begin{array}{l}19.43^{* * *} \\
(2.68)\end{array}$ & $\begin{array}{l}14.97^{* * *} \\
(2.43)\end{array}$ \\
\hline DAsym & $\begin{array}{l}-8.51^{* * *} \\
(2.76)\end{array}$ & $\begin{array}{l}-8.83^{* * *} \\
(2.90)\end{array}$ & $\begin{array}{l}-8.67^{* * *} \\
(2.04)\end{array}$ \\
\hline DChat $\times$ DAsym & $\begin{array}{l}7.85 \\
(4.91)\end{array}$ & $\begin{array}{l}9.28^{* * * *} \\
(3.60)\end{array}$ & $\begin{array}{l}8.53^{* * *} \\
(3.19)\end{array}$ \\
\hline$F(3,949)$ & $19.05^{* * *}$ & & \\
\hline$F(3,955)$ & & $88.98^{* * *}$ & \\
\hline$F(3,1908)$ & & & $69.72^{* * *}$ \\
\hline$N$ & 953 & 959 & 1912 \\
\hline
\end{tabular}

DChat is a dummy variable which takes value 1 if firms can chat and value 0 otherwise. DAsym is a dummy variable which takes value 1 if firms cost functions are asymmetric and value 0 otherwise. Newey-West standard errors in parentheses. ${ }^{*} p$-Value $<.10$, ${ }^{* *} p$-Value $<.05$.

${ }^{* * *} p$-Value $<.01$.

sellers, chat is producing near-monopoly prices, while prices are close to competitive levels when sellers could only make price announcements. ${ }^{21,22}$

We previously noted that, when sellers are symmetric, coordination is higher with price announcements compared to when there is no communication, and we find that they are yet higher when sellers can chat. From Table 3, the percentage of periods for which symmetric sellers set the same price (during periods $21-40$ ) is $18 \%$ with no communication, almost $50 \%$ with price announcements, and more than $90 \%$ with chat. Furthermore, there was near-perfect collusion in 11 of the 12 groups as firms charged identical prices starting in period 27 (or earlier) and the average market price was between 97 and 102. When sellers are asymmetric, the percentage of periods for which sellers set the same price (during periods 21-40) is 9-15\% with either no communication or price announcements and rises to almost 55\% with chat.

However, that measure understates the extent of collusion because some groups coordinated on different prices. Table 6 reports summary statistics for the 12 asymmetric groups with chat (for periods 21-40). Seven groups coordinated on identical prices near the monopoly level and another three groups coordinated on different prices (as revealed by inspecting the price and quantity paths). Sellers in group 2 alternated between a price just above 145 and a price of 145 so they took turns selling at 145 (which actually resulted in low profit because price was too high). Group 6 settled down to a stationary outcome in which the low cost seller prices at 90 and the high cost seller prices at 82 and limits its supply to 42 so that the low cost seller has residual demand of 18 . This outcome allowed them to earn the same high profit. Finally, sellers in group 10 alternated between a price of 102 and not posting a price so that each earned monopoly profit every other period. ${ }^{23}$

\footnotetext{
21 In Table 2, prices for four symmetric sellers in the Chat treatment far exceed the prices for three symmetric sellers in the Price Announcements treatment.

${ }^{22}$ With regards to the earlier expressed concern that the experimental setting may be too complex, subjects' behavior does not support that concern. As just noted for the Chat treatment, the median price is at or very close to the monopoly price which indicates that they have solved the joint profit maximization problem. For the No Communication treatment, results are consistent with previous experiments in that market price for two subjects exceeds the static Nash equilibrium price, while market price for three or more subjects is close to the static Nash equilibrium price.

${ }^{23}$ Group 4 also had a high average market price but their conduct did not settle down to any recognizable pattern.
} 
Result 3. When sellers can engage in chat then - compared to either no communication or price announcements - sellers set higher prices and coordinate more, whether they are symmetric or asymmetric and whether there are two sellers or more than two sellers. With chat, prices are often at or near monopoly levels.

Table 7 reports estimates from panel data regressions which allow us to compare the efficacy of communicating through chat with non-binding price announcements. Express communication significantly raises price. When firms are symmetric, price is higher by 19.43 and, when firms are asymmetric, the price increase is 28.71 (using the estimated coefficients for periods 21-40). The positive coefficient for the interaction term supports the claim that direct communication through chat is a more effective collusive device when firms are asymmetric, compared to price announcements. Thus, the incremental value to directly, as opposed to indirectly, communicating, is greater when firms have different cost functions.

Result 4. For the case of duopoly, the incremental effect on price of chat compared to price announcements is greater when firms are asymmetric than when they are symmetric.

\section{Concluding remarks}

The primary objectives of this project are to investigate: (1) the efficacy of non-binding price announcements in producing collusion; (2) the efficacy of unrestricted communication relative to price announcements in producing collusion, and (3) how the answers to those first two questions depend on market structure in terms of firm asymmetries and the number of firms. One main finding is that price announcements clearly increase the frequency of collusion for a symmetric duopoly but do not facilitate collusion when firms are asymmetric or there are more than two firms. The near-universal experimental finding that it is very difficult for three or more firms to coordinate on high prices when there is no communication is shown to be robust to allowing firms to communicate through price announcements. Though price announcements do raise average price with asymmetric duopolies, there is little evidence that they are able to generate stable supracompetitive outcomes. Regarding the efficacy of unrestricted communication, it is highly effective in producing collusion whether firms are identical or not and regardless of the number of firms. For all cases, prices and profits are significantly higher when sellers can engage in express communication compared to when only price announcements are available. The incremental gain of direct communication (through chat) compared to indirect communication (through price announcements) is large for all market structures but especially when firms are asymmetric and when there are more than two firms.

Our experimental evidence is consistent with the following two hypotheses. First, indirect communication through price announcements is sufficient for producing collusion in symmetric duopolies. Second, reasonably direct communication is required to produce collusion when firms are asymmetric or there are more than two firms. The evidence for that hypothesis is that collusion was widely observed when firms engage in online chat, while price announcements rarely resulted in collusion when there were more than two firms or firms had different cost functions. Of course, there are other forms of indirect communication which may succeed where price announcements failed. Also, while price announcements produced little collusion for asymmetric duopolies, higher prices were observed which may indicate failed attempts at colluding. Perhaps the addition of quantity announcements would be sufficient to result in collusion in that case, or allowing firms to announce strategies. At the same time, the asymmetry in our experiment is very mild so it is rather striking that price announcements are insufficient for coordination. In actual markets, firms are substantively asymmetric, yet it seems that price announcements have worked; for example, in the airlines industry. There is then a gap between what is being found experimentally and what has occurred in actual markets.

In terms of future research, there is more to be done in allowing for different firm asymmetries and communication protocols. The cost asymmetry could be made more extensive by assuming it applies to all units. Other forms of asymmetry to consider are capacity and product differentiation. It is especially important to investigate other types of non-express means of communication such as the announcement by a seller of a strategy. Such messages were the basis for at least two Section 5 "invitation to collude" cases pursued by the U.S. Federal Trade Commission in recent years. ${ }^{24}$ Finally, some experiments have allowed for probabilistic penalties in response to sellers choosing to engage in online chat, in order to simulate the penalties imposed by antitrust and competition law. Our design could be modified to make online chat an option. Sellers could then seek to "legally" collude through price announcements or "illegally" collude through online chat. This design would serve to identify the types of market structures for which sellers opt for express communication.

\section{Appendix A. Supplementary data}

Supplementary data associated with this article can be found, in the online version, at http://dx.doi.org/ 10.1016/j.jebo.2016.05.014.

\footnotetext{
${ }^{24}$ In the Matter of Valassis Communications, Inc., File No. 051 0008, Docket No. C-4160, April 28, 2006; and U-Haul International, Inc. Docket No. C-4294 Complaint, July 14, 2010.
} 


\section{References}

Andersson, O., Holm, H.J., 2013. Speech is silver, silence is golden. Games 4, 497-507.

Andersson, O., Wengström, E., 2007. Do antitrust laws facilitate collusion? Experimental evidence on costly communication in duopolies. Scand. J. Econ. 109, 321-339.

Argenton, C., Müller, W., 2012. Collusion in experimental bertrand duopolies with convex costs: the role of cost asymmetry. Int. J. Ind. Org. $30,508-517$. Bigoni, M., Fridolfsson, S.-O., Le Coq, C., Spagnolo, G., 2012. Fines, leniency, and rewards in antitrust. RAND J. Econ. 43, $368-390$.

Borenstein, S., 2004. Rapid price communication and coordination: the airline tariff publishing case (1994). In: Kwoka Jr., J.E., White, L.J. (Eds.), The Antitrust Revolution. , 4th ed. Oxford University Press, New York.

Cason, T., 1995. Cheap talk price signaling in laboratory markets. Inf. Econ. Policy 7, 183-204.

Cason, T., Davis, D.D., 1995. Price communications in a multi-market context: an experimental investigation. Rev. Ind. Org. 10, 769-787.

Cason, T., 2008. Price signaling and 'cheap talk' in laboratory posted offer markets. Handbook of Experimental Economics Results, vol. 1. Elsevier.

Cooper, D.J., Kühn, K.-U., 2014. Communication, renegotiation, and the scope for collusion. Am. Econ. J.: Microecon. 6, $247-278$.

Cramton, P., Schwartz, J.A., 2000. Collusive bidding: lessons from the FCC spectrum auctions. J. Regul. Econ. 17, $229-252$.

Davis, D.D., Holt, C.A., 1998. Conspiracies and secret discounts in laboratory markets. Econ. J. 108, $736-756$.

Dijkstra, P.T., Haan, M.A., Schoonbeek, L., 2011. Leniency Programs and the Design of Antitrust: Experimental Evidence with Unrestricted Communication. Working paper. University of Groningen.

Doyle, M.P., Snyder, C.M., 1999. Information sharing and competition in the motor vehicle industry. J. Polit. Econ. 107, $1326-1364$.

Dufwenberg, M., Gneezy, U., 2000. Price competition and market concentration: an experimental study. Int. J. Ind. Org. 18, 7-22.

Dugar, S., Mitra, A., 2009. The Size of the Cost Asymmetry and Bertrand Competition: Experimental Evidence. Working paper. University of Calgary and University of Arizona.

Eichenwald, K., 2000. The Informant. Broadway Books, New York.

Engel, C., 2007. How much collusion? A meta-analysis of oligopoly experiments. J. Compet. Law Econ. 3, 491-549.

Fair Trade Commission Decision of October 14, 2004. Downloaded from www.apeccp.org.tw/doc/Taipei/Case/D094q108.htm (accessed 26.04.16).

Fonseca, M.A., Normann, H.-T., 2008. Mergers, asymmetries and collusion: experimental evidence. Econ. J. 118, 387-400.

Fonseca, M.A., Normann, H.-T., 2012. Explicit vs. tacit collusion - the impact of communication in oligopoly experiments. Eur. Econ. Rev. 56, $1759-1772$.

Friedman, J.W., 1967. An experimental study of cooperative duopoly. Econometrica 35, 379-397.

Friedman, D., Huck, S., Oprea, R., Weidenholzer, S., 2015. From imitation to collusion: long-run learning in a low-information environment. J. Econ. Theor. $155,185-205$.

Haan, M.A., Schoonbeek, L., Winkel, B.M., 2009. Experimental results on collusion: the role of information and communication. In: Hinloopen, J., Normann, H.-T. (Eds.), Experiments and Competition Policy. Cambridge University Press, Cambridge.

Harrington Jr., J.E., 1991. The determination of price and output quotas in a heterogeneous cartel. Int. Econ. Rev. 32, 767-792.

Harrington Jr., J.E., 2006. How do cartels operate? Found. Trends Microecon. 2 (1).

Harrington Jr., J.E., Hernan-Gonzalez, R., Kujal, P., 2013. The Relative Efficacy of Price Announcements and Express Communication for Collusion: Experimental Findings. Working paper. University of Pennsylvania, The Wharton School.

Harstad, R., Martin, S., Normann, H.-T., 1998. Intertemporal pricing schemes: experimental tests of consciously parallel behavior in oligopoly. In: Phlips, L. (Ed.), Applied Industrial Organization. Cambridge University Press, Cambridge.

Hinloopen, J., Soetevent, A.R., 2008. Laboratory evidence on the effectiveness of corporate leniency programs. RAND J. Econ. $39,607-616$.

Holt, C.A., Davis, D., 1990. The effects of non-binding price announcements on posted-offer markets. Econ. Lett. 34, 307-310.

Huck, S., Normann, H.-T., Oechssler, J., 2004. Two are few and four are many: number effects in experimental oligopolies. J. Econ. Behav. Org. 53, 435-446. Issac, R.M., Plott, C., 1981. The opportunity for conspiracy in restraint of trade. J. Econ. Behav. Org. 2, 1-30.

Issac, R.M., Ramey, V., Williams, A., 1984. The effects of market organization on conspiracies in restraint of trade. J. Econ. Behav. Org. 5, 191-222.

Kaplow, L., 2013. Competition Policy and Price Fixing. Princeton University Press, Princeton.

Marshall, R.C., Marx, L.M., 2012. The Economics of Collusion - Cartels and Bidding Rings. The MIT Press, Cambridge, MA.

Mason, Charles F., Phillips, Owen R., 1997. Information and cost asymmetry in experimental duopoly markets. Rev. Econ. Stat. 79, 290-299.

Mason, Charles F., Phillips, Owen R., Nowell, Clifford, 1992. Duopoly behavior in asymmetric markets: an experimental evaluation. Rev. Econ. Stat. 74, $662-670$.

Miklós-Thal, J., 2011. Optimal collusion under cost asymmetry. Econ. Theor. 46, 99-125.

Normann, H.-T., 2008. Experimental economics. In: Issues in Competition Law and Policy, 773, ABA Section of Antitrust Law.

Potters, J., 2009. Transparency about past, present, and future conduct: experimental evidence on the impact on competitiveness. In: Hinloopen, J.,

Normann, H.-T. (Eds.), Experiments and Competition Policy. Cambridge University Press, Cambridge.

Rojas, C., 2012. The role of information and monitoring on collusion. RAND J. Econ. 43, 78-109.

Scherer, F.M., 1980. Industrial Market Structure and Economic Performance, 2nd ed. Houghton Mifflin, Boston. 